- ACORN Australan college of | JOURNAL OF PERIOPERATIVE NURSING

Volume 34 | Issue 2

Article 7

$5-31-2021$

\title{
Still more to do to improve perioperative safety and prevent patient harm
}

Follow this and additional works at: https://www.journal.acorn.org.au/jpn

Part of the Perioperative, Operating Room and Surgical Nursing Commons

(c) (i)

This work is licensed under a Creative Commons Attribution 4.0 License.

\section{Recommended Citation}

Duff, Jed (2021) "Still more to do to improve perioperative safety and prevent patient harm," Journal of Perioperative Nursing: Vol. 34 : Iss. 2 , Article 7.

Available at: https://doi.org/10.26550/2209-1092.1127

https://www.journal.acorn.org.au/jpn/vol34/iss2/7

This Editorial is brought to you for free and open access by Journal of Perioperative Nursing. It has been accepted for inclusion in Journal of Perioperative Nursing by an authorized editor of Journal of Perioperative Nursing. 
Professor Jed Duff

PhD, RN, FACORN

Editor, Journal of Perioperative Nursing

Professor, School of Nursing Faculty of Health, Queensland University of Technology Nursing and Midwifery Research Centre, Royal Brisbane and Women's Hospital

journaleditor@acorn.org.au

\section{Still more to do to improve perioperative safety and prevent patient harm}

Above all else, the raison d'être of the perioperative nurse is to maintain surgical asepsis and patient safety. However, despite all current efforts, there is still an unacceptably high number of our patients experiencing preventable adverse events. A recent systematic review found that 20 per cent of surgical patients are harmed during their hospital stay, with 50 per cent of these harms judged as wholly preventable'. This equates to approximately 200000 Australian patients suffering injury or death each year because of unsafe and poor-quality surgical care.

The latest Australian Institute of Health and Welfare report draws attention to the epidemic of adverse events associated with surgery². The report highlights Australia's inferior performance on key performance indicators compared to other member countries of the Organisation for Economic Co-operation and Development (OECD). For example, our incidence of unintentionally retained surgical items is 63 per cent higher, deep venous thrombosis following hip and knee surgery is 86 per cent higher and post-operative pulmonary embolism is more than double (211 per cent higher).

One of the most significant preventable adverse events related to the quality of our perioperative care is surgical site infections (SSIs). In Australia, 3.6 per cent of patients experience an SSI, accounting for over one-quarter of all hospitalacquired infections (HAls) ${ }^{3}$. These infections are associated with significant adverse post-operative outcomes for the patient, family and health service. They lead to extended hospital stays, higher readmission rates and increased health care costs, not to mention the emotional, physical and financial burden to patients ${ }^{4}$.
The most egregious preventable adverse events are called 'sentinal' events in Australia and 'never' events in many other countries. Sentinel events are a subset of adverse events that are 1) wholly preventable, 2) independent of a patient's overall health condition and 3 ) result in serious patient harm or death. Sentinal events indicate deficiencies in hospital systems and processes that represent compromised quality of care and patient safety. You will see that many of the listed sentinal events are related to perioperative care in acknowledgment of the high volume, high-risk environment.

Historically, states and territories interpreted and reported these events differently, requiring caution when interpreting the data (see Table 1). In 2019, the Sentinel Events Review Steering Committee was convened to revise the list and standardise reporting. The revised list (see box) contains ten events: five are as previously listed, three replace 'procedures involving the wrong patient or body part', and two are new, were not previously listed - 'use of physical or mechanical restraint resulting in serious harm or death' and 'use of an incorrectly positioned oro- or nasogastric tube resulting in serious harm or death'. Two events 
Table 1: Australian sentinal event data 2015 to 2019

\begin{tabular}{|c|c|c|c|c|c|}
\hline Selected sentinel event & 2015 & 2016 & 2017 & 2018 & 2019 \\
\hline $\begin{array}{l}\text { Procedures involving the wrong patient or body part resulting in death } \\
\text { or major permanent loss of function }\end{array}$ & 1 & 5 & 1 & 1 & 1 \\
\hline Suicide of a patient in an inpatient unit & 30 & 28 & 20 & 24 & 17 \\
\hline $\begin{array}{l}\text { Retained instruments or other material after surgery requiring re- } \\
\text { operation or further surgical procedure }\end{array}$ & 35 & 26 & 23 & 28 & 28 \\
\hline Intravascular gas embolism resulting in death or neurological damage & 5 & 4 & 3 & 3 & 1 \\
\hline $\begin{array}{l}\text { Haemolytic blood transfusion reaction resulting from ABO (blood } \\
\text { group) incompatibility }\end{array}$ & 1 & 2 & 0 & 2 & 0 \\
\hline $\begin{array}{l}\text { Medication error leading to the death of a patient reasonably believed } \\
\text { to be due to incorrect administration of drugs }\end{array}$ & 14 & 7 & 10 & 16 & 12 \\
\hline Maternal death associated with pregnancy, birth or the puerperium & 9 & 9 & 7 & 2 & 6 \\
\hline Infant discharged to the wrong family & 0 & 0 & 0 & 1 & 0 \\
\hline Total & 101 & 82 & 65 & 80 & 65 \\
\hline
\end{tabular}

\section{Revised sentinal event list 2020}

1. Surgery or other invasive procedure performed on the wrong site resulting in serious harm or death

2. Surgery or other invasive procedure performed on the wrong patient resulting in serious harm or death

3. Wrong surgical or other invasive procedure performed on a patient resulting in serious harm or death

4. Unintended retention of a foreign object in a patient after surgery or other invasive procedure resulting in serious harm or death

5. Haemolytic blood transfusion reaction resulting from $A B O$ incompatibility resulting in serious harm or death

6. Suspected suicide of a patient in an acute psychiatric unit or acute psychiatric ward

7. Medication error resulting in serious harm or death

8. Use of physical or mechanical restraint resulting in serious harm or death

9. Discharge or release of an infant or child to an unauthorised person

10. Use of an incorrectly positioned oro- or nasogastric tube resulting in serious harm or death previously listed are not included in the revised list - 'maternal death associated with pregnancey, birth or the puerperium' and 'intravascular gas embolism resulting in death or neurological damage'.

Many perioperative nurses have heard the saying, 'the standard you walk past is the standard you accept'. This saying eloquently sums up the challenge of overcoming normalised deviance. Normalisation of deviance is a phenomenon where individuals and teams deviate from what is known to be an acceptable standard until the adopted way of practice becomes normalised (Figure 1). The Chernobyl nuclear accident and the NASA Challenger and Columbia Space Shuttle disasters are two infamous examples where incremental deviation from acceptable practice resulted in total catastrophe. In the perioperative environment, normalised deviance eventually leads to serious adverse events.

The safety of our patients is a collective responsibility that requires us to work together to create a safe 


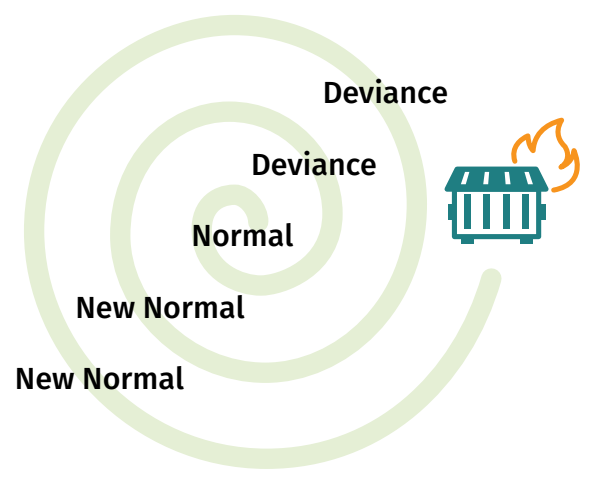

Figure 1: Development of
normalised deviance

environment. Two programs that have frequently been used in other countries to promote teamwork and safety culture are TeamSTEPPS 5 and CUSP.

\section{TeamSTEPPS (Team Strategies and Tools to Enhance Performance and Patient Safety)}

TeamSTEPPS 5 is an evidence-based program aimed at optimising performance among health care teams, enabling them to respond quickly and effectively to whatever situations arise. It was developed in the USA by the Agency for Healthcare
Research and Quality and the Department of Defense to improve collaboration and communication. The TeamSTEPPS program addresses four teachable-learnable skills: communication, leadership, situation monitoring and mutual support. TeamSTEPPS is freely available online, including individual modules related to the perioperative setting.

\section{CUSP (Comprehensive Unit- based Safety Program)}

The Comprehensive Unit-based Safety Program (CUSP) ${ }^{6}$ is a method that can help clinical teams make care safer by combining improved teamwork, clinical best practices and the science of safety. The Core CUSP toolkit gives clinical teams the training resources and tools to apply the CUSP method and build their capacity to address safety issues. A perioperative-specific toolkit is freely available online to help clinical teams adopt the CUSP method to make care safer. The toolkit is modular, and each module includes teaching materials, resources to support change, facilitator notes, presentation slides, tools and videos.

I encourage you to explore these and other similar programs to improve teamwork and perioperative safety and welcome you to share your experiences with your colleagues here in the Journal of Perioperative Nursing.

\section{References}

1. Panagioti M, Khan K, Keers RN, Abuzour A Phipps D, Kontopantelis E et al. Prevalence, severity, and nature of preventable patient harm across medical care settings: Systematic review and meta-analysis. BMJ 2019;366:14185.

2. Australian Institute of Health and Welfare (AlHW). Australia's hospitals at a glance 2017-18. Canberra: AlHW; 2019.

3. Russo PL, Stewardson AJ, Cheng AC, Bucknall T, Mitchell BG. The prevalence of healthcare associated infections among adult inpatients at nineteen large Australian acute-care public hospitals: A point prevalence survey. Antimicrobial Resistance \& Infection Control 2019;8(1):114.

4. Brown B, Tanner J, Padley W. 'This wound has spoilt everything': Emotional capital and the experience of surgical site infections. Sociology of health \& illness 2014;36(8):11711187.

5. Agency for Healthcare Research and Quality (AHRQ). TeamSTEPPS [Internet]. Rockville, MD; 2014 [updated 2020 January; cited 2021 May 24]. Available from www.ahrq.gov/ teamstepps/index.html.

6. Agency for Healthcare Research and Quality (AHRQ). CUSP Method [Internet]. Rockville, MD; 2012 [updated 2019 August; cited 2021 May 24]. Available from https://www.ahrq. gov/hai/cusp/index.html. 